\title{
In vitro Assessment of Antioxidant and Antimicrobial Potential of Lactobacillus gasseri Strains Isolated from Human Milk and Infant Faeces
}

\author{
Sonakshi Rastogi ${ }^{1}$, Vineeta Mittal $^{2}$ and Aditi Singh ${ }^{1 *}$ (D) \\ ${ }^{1}$ Amity Institute of Biotechnology, Amity University Uttar Pradesh, Lucknow Campus, Gomti Nagar Extension, \\ Near Malhaur Railway Station, Lucknow - 226 028, India. ${ }^{2}$ Department of Microbiology, Dr. Ram Manohar Lohia \\ Institute of Medical Sciences, Vibhuti Khand, Lucknow - 226010 , India.
}

\begin{abstract}
The present work demonstrates the antagonistic and antioxidant property of Lactobacillus gasseri LGS22 (MN258931), Lactobacillus gasseri MVS25(MN396621) isolated from human milk and Lactobacillus gasseri LBM220 (MN097539) isolated from exclusively breast-fed infant faeces. Antagonistic potential was assayed using agar well diffusion method against 17 food-borne and enteric pathogens. Further, in order to characterize the nature of inhibitory metabolites in culture supernatant, several preliminary experiments such as $\mathrm{pH}$ adjustment,treatment with protease, catalase and heat were performed. In addition, quantitative estimation of antimicrobial activity was performed using Time-kill assay against indicator pathogen Sh. flexneri type 2. Strains were further evaluated for antioxidant action such as scavenging of hydroxyl radical, DPPH radical and ABTS+ radical. The capacity to resist $0.4 \mathrm{mM}$, $0.8 \mathrm{mM}$ and $1 \mathrm{mM}$ hydrogen peroxide for $16 \mathrm{~h}$ was also studied. Results report the efficient inhibitory potential of Lact. gasseri strains with zone sizes ranging from moderate to very strong inhibition $(10-22 \mathrm{~mm})$ against most of the indicator pathogens employed in the current study. Also, inhibitory action of cell-free culture supernatant of isolates LBM220 and MVS25 when adjusted to pH 6.5 was significantly reduced, elucidating the production of organic acids, while isolate LGS22 produced hydrogen peroxide as inhibitory metabolite. Lact. gasseri isolates were found to significantly scavenge free radicals, with scavenging potential in range of (80.687- 26.552\%). It is concluded that these three Lact. gasseri isolates may be explored more for their bio-potential as food additive with antioxidant and antimicrobial activities.
\end{abstract}

Keywords: Lactobacillus species, LAB, Infant faeces, Human milk, Antagonistic activity, Antioxidant activity

*Correspondence: asingh3@lko.amity.edu; +91 9839009661

(Received: March 03, 2020; accepted: June 02, 2020)

Citation: Rastogi S, Mittal V, Singh A. In vitro Assessment of Antioxidant and Antimicrobial Potential of Lactobacillus gasseri Strains Isolated from Human Milk and Infant Faeces. J Pure Appl Microbiol. 2020;14(2):1305-1315. doi: 10.22207/JPAM.14.2.26

(C) The Author(s) 2020. Open Access. This article is distributed under the terms of the Creative Commons Attribution 4.0 International License which permits unrestricted use, sharing, distribution, and reproduction in any medium, provided you give appropriate credit to the original author(s) and the source, provide a link to the Creative Commons license, and indicate if changes were made. 


\section{INTRODUCTION}

Recently, incidences of food-borne diseases are growing in most developing countries as food quality control is on little priority owing to inadequate funds. Food spoilage and enteric pathogens are responsible for high mortality and morbidity accounting to fifth principle determinant of death of all age groups worldwide ${ }^{1}$. Common among them are Shigella spp., Salmonella spp., Staphylococcus aureus, Listeria monocytogenes and Escherichia coli ${ }^{2}$. So far, several synthetic chemical antibiotics have been extensively employed as therapeutics. However, their safety and long-term consequences are highly doubted. In order to cater this need, use of Lactobacillus spp. and their metabolites were widely explored by food technologists/researchers owing to its diverse antimicrobial, preservation and therapeutic attributes. With development of probiotic research, role of Lactobacillus spp. in restoration of gastrointestinal microflora, alleviation of ilial inflammatory response, augmentation of gut immunological barrier functions and antagonistic ability clearly demonstrate their capacity to manage specific enteric diseases. Additionally, antimicrobial potential of these beneficial microbes and/or extracellular antimicrobial metabolites offers propitious prospects for their use in infant formula feeds, food preservation and veterinary medical supplements. So far, voluminous literatures are available that report the competence of genus lactobacilli in restraining infections due to both Gram-negative and Gram-positive spoilage and pathogenic bacteria ${ }^{3,4}$. Combined application of Lactobacilli and antibiotic(s) orally has shown to be effective in curbing enteric infections, with lesser antibiotics dose needed. Also, it may result in replenishment of the gastrointestinal microflora, ultimately benefitting the host and preventing antibiotics side effects ${ }^{5}$. Human milk is a genesis of commensal infant gastrointestinal tract microflora, thus it is obvious that the microbial composition of infant faeces reflects that of breast milk ${ }^{6}$. Species of genus Lactobacilli, such as Lact. acidiphilus, Lact. rhamnosus, Lact. fermentum, Lact. gasseri and Lact. plantarum are among the most prevailing species in the gastrointestinal tract of the infant and they help in alleviation of several common enteric infections, though mechanism of their action is limited. Studied mechanisms include production of inhibitory metabolites, competitive exclusion of pathogenic microbes in the gut, strengthening of the intestinal barrier and modulation of host immune system ${ }^{7}$. Earlier, Toba et al. (1991) ${ }^{8}$ reported antimicrobial property of Lact. gasseri LA39 from infant stool sample owing to its production of bacteriocin, gassericin A. Majority of commercial probiotics available nowadays have been of human or food/dairy origin. Although literatures voicing and assuring antimicrobial activity of lactobacilli are available, only limited researches uncover the antimicrobial efficacy of breast milk lactobacilli. In lieu of the above facts, present work was outlined to study the potency of CFCS of Lactobacillus gasseri strains exclusively isolated from breast milk and infant faeces against wide range of human and foodborne pathogenic bacteria.

When enteric pathogens proliferate excessively the intestinal tract, they induce endotoxin accumulation in the blood, thereby causing significant oxidative stress ${ }^{9}$, leading to cell membrane damage, protein denaturation and incorrect DNA replications. Oxidative stress is correlated with initiation of multiple disorders such as cancer, lung injury, diabetes and atherosclerosis. Although, human body is endowed with repair systems and enzymatic antioxidant defences such as glutathione peroxidase (GPx), glutathione reductase (GR), superoxide dismutase (SOD) as well as non-enzymatic antioxidant defences such as to copherols, thioredoxin, glutathione, ascorbic acid to protect against oxidative damage ${ }^{10}$. Sometimes they are insufficient to cater to it efficiently. Therefore, numerous synthetic antioxidants such as butylated hydroxyanisole and butylated hydroxytoluene are consumed to resist damage, though their usage is highly questioned as they may cause cancer and liver damage ${ }^{11}$. Thus, recently, focus on developing safer and effective natural antioxidant agents is gaining momentum ${ }^{12}$. So far, several studies have reported the potential role of lactobacilli as antioxidant. Lact. gasseri NLRI-312 isolated from stool sample of Korean infant was found to reduce $\mathrm{H}_{2} \mathrm{O}_{2}$ induced cellular lipid and DNA damage ${ }^{13}$. Similarly, Lacto. gasseri 4M13 isolated from infant faeces displayed high DPPH and ABTS scavenging ability ${ }^{14}$. Thus, Lact. 
gasseri strains were also tested for scavenging potential of DPPH, ABTS ${ }^{+}$, Hydroxyl free radicals as well as resistance to hydrogen peroxide.

\section{MATERIALS AND METHODS \\ Microbial cultures and culture media}

For the purpose of isolation, 12 human milk samples and 18 breast-fed infant feaces samples were aseptically collected. All samples were cultured in lactobacillus selective De Man Rogosa Sharpe (MRS) medium (Himedia, India) at $37^{\circ} \mathrm{C}$ under anaerobic condition ( $80 \%$ $\left.\mathrm{N}_{2}, 10 \% \mathrm{CO}_{2}, 10 \% \mathrm{H}_{2}\right)$ generated by anaerobic system (Anoxomat III, USA) for $48 \mathrm{~h}$. A total of 162 isolates from human milk samples and 230 isolates from infant faecal samples, were isolated.Based on preliminary antimicrobial and antioxidant (by DPPH free radical method) screening of the isolates, the three potential strains which displayed significant inhibitory and scavenging capacity, were selected. Further identification was done using MALDI-TOF, while confirmation was done by $16 \mathrm{~S}$ rRNA sequencing. Sequences were submitted in GenBank under accession number: Lactobacillus gasseri LBM220 (MN097539) from infant faeces and Lactobacillus gasseri LGS22 (MN258931) and Lactobacillus gasseri MVS25(MN396621) from human milk. The study was approved by institutional ethical review board of Dr Ram Manohar Lohia Institute of Medical Sciences, Lucknow (Ref. No. 2784/ RMLIMS/2018). The strains were stored for shortterm period at $4^{\circ} \mathrm{C}$ and for long-term period at $-80^{\circ} \mathrm{C}$ with $5 \%$ skim milk. All pathogenic strains employed in present study were procured from $\mathrm{Dr}$ Ram Manohar Lohia Institute of Medical Sciences, Lucknow and aerobically cultured in Brain heart infusion broth (BHI)(Oxoid, UK). Clinical strains used were Salmonella typhimurium, Salmonella paratyphi $\mathrm{T}(\mathrm{H})$, Salmonella typhi $\mathrm{T}(\mathrm{H})$, Serratia fecaria, Corynebacterium diphtheria, Shigella boydii, Listeria monocytogenes, Shigella sonnei, Shigella dysenteriae, Staphylococcus aureus ATCC 25923, Shigella flexneri type2, and ATCC indicator strains used were Enterococcus faecalis ATCC51299, Klebseilla oxytoca ATCC-700324,Proteus vulgaris ATCC-6380, Escherichia coli ATCC-25922, Pseudomonas aeruginosa ATCC-27853, Klebseilla pneumonia ATCC 700602.

\section{Antagonistic activity}

Antimicrobial activity of Lact. gasseri strains against seventeen toxic enteric pathogens was determined as described by Rastogi et al., $(2019)^{15}$. Both isolates were anaerobically cultured in MRS broth for $48 \mathrm{~h}$, followed by centrifugation at $12000 \mathrm{xg}$ for $15 \mathrm{~min}$ at $4^{\circ} \mathrm{C}$. Supernatants were collected and filter sterilised using $0.2 \mu$ cellulose acetate paper to remove residual bacterial cells. The cell-free culture supernatants (CFCS) were then used to determine the antibacterial activity. Also, all indicator pathogens were aerobically grown overnight in $\mathrm{BHI}$ broth at $37^{\circ} \mathrm{C} .20 \mathrm{ml} \mathrm{BHI}$ soft agar containing test pathogen (about $10^{8} \mathrm{CFU}$ / $\mathrm{ml}$ ) was plated and was kept to solidify. Wells of $6 \mathrm{~mm}$ diameter were made and filled with $80 \mu \mathrm{l}$ of CFCS. Plates were kept for 2 hours at $4^{\circ} \mathrm{C}$ for rapid diffusion and then at $37^{\circ} \mathrm{C}$ overnight. Each plate was examined for inhibitory halo zones after incubation. The inhibitory activity was interpreted as very strong $(>17 \mathrm{~mm})$, strong $(14-24 \mathrm{~mm})$, intermediate $(10-13 \mathrm{~mm})$ and weak $(7-9 \mathrm{~mm})$ as reported by Sirichokchatchawan et al.,(2018) ${ }^{16}$. Assay was carried out in three replicates and results are expressed as mean of inhibition zones \pm SD.

To elucidate the effect of different treatments on antagonistic potential of CFCS of Lact. gasseri strains

Effect of various treatments on inhibitory action of CFCS of Lact. gasseri strains was examined according to Yu et al.,(2015) ${ }^{17}$ with minor changes. Agar well diffusion assay was employed against test pathogen $S h$. flexneri. Untreated CFCS served as control.

Effect of $\mathrm{pH}$ on antagonistic potentialCFCS of Lact. gasseri strains was adjusted to $\mathrm{pH}$ 6.5 using sterile $1 \mathrm{~N}$ sodium hydroxide, followed by agar well diffusion assay using treated CFCS in order to determine the outcome of $\mathrm{pH}$ change on its inhibitory ability.

Effect of catalase on antagonistic potential- To ascertain the antimicrobial activity due to hydrogen peroxide, $0.5 \mathrm{mg} / \mathrm{ml}$ catalase (Himedia, India) enzyme was added to CFCS of Lact. gasseri strains, followed by agar well diffusion assay to observe the change in inhibitory potential. Effect of protease on antagonistic potential- To assess the inhibitory activity due to bacteriocin 
and/ or inhibitory peptides, CFCS of Lact. gasseri strains was treated with $1 \mathrm{mg} / \mathrm{mL}$ protease (Himedia, India) for $1 \mathrm{~h}$. Thereafter, the enzyme was denatured at $60^{\circ} \mathrm{C}$ for $20 \mathrm{~min}$, followed by agar well diffusion assay to observe the alterations in inhibitory activity.

Effect of high temperature on antagonistic potential- Lact. gasseri strains' CFCS was subjected to high temperature $\left(60^{\circ} \mathrm{C}\right.$ for $\left.1 \mathrm{~h}\right)$, and then tested for its antibacterial potential as described above using this treated CFCS.

Time-kill assay with CFCS of Lact. gasseri strains on indicator pathogen -Sh. flexneri

Time-kill assay was performed by culturing Sh. flexneri with CFCS of Lact. gasseri strains as outlined by Zhang et al.(2011) ${ }^{18}$ with some modifications. To perform, $500 \mu \mathrm{l}$ of $S h$. flexneri $\left(10^{8} \mathrm{cfu} \mathrm{m}^{-1}\right)$ was mixed with $5 \mathrm{ml}$ each CFCS as mentioned above, viz. CFCS (pH 6.5), CFCS (protease treated), CFCS (catalase treated), CFCS (High temperature treated) and MRS broth ( $\mathrm{pH} 6.5$; as control), followed by aerobic incubation at $37^{\circ} \mathrm{C}$. Aliquots were removed after predefined intervals $(t=0,2,4,8,16 h)$, serially diluted and each dilution plated on $\mathrm{BHI}$ to assess the viability of pathogens after incubation. The assay was carried out in three replicates and results reported as mean of log cfu $\mathrm{ml}^{-1} \pm \mathrm{SD}$.

Assay antioxidant potential of Lact. gasseri strains DPPH free radical-scavenging ability

2,2-diphenyl-1-picrylhydrazyl(DPPH; Himedia, India) radical scavenging capability of Lact. gasseri LBM220 was measured as described by Nithya et al.(2013) ${ }^{19}$. Briefly, $48 \mathrm{~h}$ anaerobically grown Lact. gasseri strains were centrifuged $\left(12000 \mathrm{xg}, 10 \mathrm{~min}, 4^{\circ} \mathrm{C}\right)$ to collect culture supernatant. Two $\mathrm{ml}$ DPPH solution (6 $\mathrm{mg} / 100 \mathrm{ml}$ of methanol) was added to $500 \mu \mathrm{l}$ of culture supernatant to prepare test solution. Blank comprised of $2 \mathrm{ml}$ methanol in $500 \mu \mathrm{l}$ of supernatant. Positive control used was L-ascorbic acid (Himedia, India). Both test and control tubes were thoroughly vortexed and kept in dark for 25 min. Absorbance (517 $\mathrm{nm}$ ) was recorded using Nano Drop Spectrophotometer(DS-11, Denovix, USA).

DPPH radical scavenging $\%=\left\{1-\left[A_{517}\right.\right.$ sample$A_{517}$ blank/A $A_{517}$ control]\} $\times 100$

$\mathrm{ABTS}^{+}$radical scavenging ability

2,2'-azino-bis(3-ethylbenzothiazoline-6- sulfonic acid)(ABTS ${ }^{+}$) radical scavenging ability of Lact. gasseri strains were assayed by a method given by Shi et al., $(2019)^{20}$ with some changes. 2,2'-Azino-bis-(3-ethylbenzothiazoline-6-sulfonic acid) diammonium salt (Himedia, India) stock solution was prepared and kept overnight in the dark at $25^{\circ} \mathrm{C}$. Thereafter, $\mathrm{ABTS}^{+}$solution was adjusted to $0.700 \pm 0.05$ absorbance $(735 \mathrm{~nm})$ with methanol. Culture supernatant $(100 \mu \mathrm{l})$ was added to $3.0 \mathrm{ml} \mathrm{ABTS}{ }^{+}$solution, followed by measuring absorbance at $735 \mathrm{~nm}$. L-ascorbic acid was used as positive control. Blank was prepared by mixing $100 \mu \mathrm{l}$ methanol or MRS broth. Percentage scavenging was calculated as follows:

$\mathrm{ABTS}^{+}$radical cation scavenging $\%=\left\{1-\left[\mathrm{A}_{734}\right.\right.$ sample$\mathrm{A}_{734}$ blank $/ \mathrm{A}_{734}$ control] $\} \times 100$

\section{Hydroxyl radical scavenging ability}

The capacity of Lact. gasseri strains to scavenge hydroxyl radical was evaluated according to modified protocol of Achuthan et al.,(2012) ${ }^{21}$. Lact. gasseri strains were anaerobically grown in MRS broth at $37^{\circ} \mathrm{C}$ for 48 $\mathrm{h}$ and centrifuged $\left(1200 \mathrm{xg}, 10 \mathrm{mins}, 4^{\circ} \mathrm{C}\right)$ to obtain culture supernatant. For generation of hydroxyl radicals, $1 \mathrm{ml}$ 1,10-phenanthroline(Himedia), $1.5 \mathrm{ml}$ phosphate buffer saline $(\mathrm{pH} 7.4), 1 \mathrm{ml}$ $(0.01 \% \mathrm{v} / \mathrm{v}) \mathrm{H}_{2} \mathrm{O}_{2}$ and $1 \mathrm{ml} \mathrm{FeSO} \mathrm{m}_{4}$ were mixed in the solution Briefly, $1.0 \mathrm{ml}$ culture supernatant was added to solution containing generated hydroxyl radical, followed by $30 \mathrm{~min}$ incubation at $25^{\circ} \mathrm{C}$, thereby recording absorbance $(536 \mathrm{~nm})$ using NanoDrop spectrophotometer. Positive control was L-ascorbic acid. The results were expressed as follows:

$\%$ hydroxyl radical scavenging $=\left\{1-\left[\mathrm{A}_{536}\right.\right.$ sample$A_{536}$ blank $/ A_{536}$ control- $A_{536}$ blank $\left.]\right\} \times 100$

Where, $A_{536}$ sample is the absorbance of test solution in presence of Culture supernatants, $A_{536}$ control is the absorbance in presence culture supernatant but where $\mathrm{H}_{2} \mathrm{O}_{2}$ in test solution was replaced with double distilled water and $A_{536}$ blank is the absorbance without culture supernatant in test solution which is replaced with MRS broth.

\section{Resistance to Hydrogen peroxide}

Ability of Lact. gasseri strains to resist hydrogen peroxide was carried out as elucidated by Li et al.,(2012)22 with minor changes. Lact. gasseri strains were anaerobically grown in MRS broth at $37^{\circ} \mathrm{C}$ for $48 \mathrm{~h}$. Thereafter, $900 \mu$ l of MRS broth supplemented with $1 \%(\mathrm{v} / \mathrm{v}) 0.4 \mathrm{mM}, 0.8 \mathrm{mM}$ and 
$1.0 \mathrm{mM}$ hydrogen peroxide $\left(\mathrm{H}_{2} \mathrm{O}_{2} ;\right.$ Himedia, India) was inoculated with $100 \mu \mathrm{l}$ of test strain culture, followed by $16 \mathrm{~h}$ anaerobic incubation at $37^{\circ} \mathrm{C}$. The culture growth was estimated by recording absorbance $(600 \mathrm{~nm})$. Control was MRS culture broth without $\mathrm{H}_{2} \mathrm{O}_{2}$ supplement. Assay was carried out in triplicates and results given as mean \pm SD.

\section{Statistical analysis}

All the experiments were performed in three parallel replicates and the results are given as mean \pm standard deviation of triplicate values.

\section{RESULTS}

\section{Antimicrobial activity}

The capacity of all three Lact. gasseri isolates to antagonise the growth of 17 pathogens was determined in the present study. Culture supernatants of all studied Lact. gasseri strains inhibited almost all indicator pathogens to varying levels, with inhibition zones ranging in size from 9-22 $\mathrm{mm}$ as presented in Fig. 1. Infant faeces isolated strain LBM220 exhibited strongest inhibition against E.coli ATCC-25922 with inhibition halo of $19 \mathrm{~mm}$, followed by Sh. flexneri $(17 \mathrm{~mm})$, Salm. typhimurium and Sh. sonnei $(16 \mathrm{~mm})$, while minimum inhibitory zone was observed for Staph. aureus and L. monocytogenes $(6 \mathrm{~mm})$. While human milk isolated strains displayed superior antimicrobial activity with greater inhibitory zone sizes. Isolate LGS22 displayed maximum inhibition for Sh. boydi and Sh. flexneri $(21 \mathrm{~mm})$, followed by Salm. typhimurium and Entero. faecalis ATCC-51299 (18 mm). While strain MVS25 exhibited maximum inhibition against Sh. sonnei (22 mm), Salm. typhi(T) (19 mm), followed by Sh. flexneri, Coryne diphtheria, Pr. vulgaris and Salm. typhimurium (inhibitory zone size of $18 \mathrm{~mm}$ ). Results obtained in the present study clearly elucidate the fact that Lact. gasseri strains from human origin are effective in inhibiting growth of human and food-borne pathogenic microbes.

Effect of multiple treatments on antimicrobial activity of CFCS of Lact. gasseri LBM220

On adjusting the CFCS of Lact. gasseri isolates to $\mathrm{pH}$ 6.5, both LBM220 and MVS25 showed dramatic reduction in antimicrobial activity, clearly suggesting that the antimicrobial ability was pH-dependent, while LGS22 showed significant inhibitory zones. Similarly, CFCS of both LBM220 and MVS25 isolates when tested for the production of hydrogen peroxide using catalase enzyme, resulted in no significant elimination of its antibacterial activity, while LGS22 displayed reduction in its inhibitory potential. This strongly

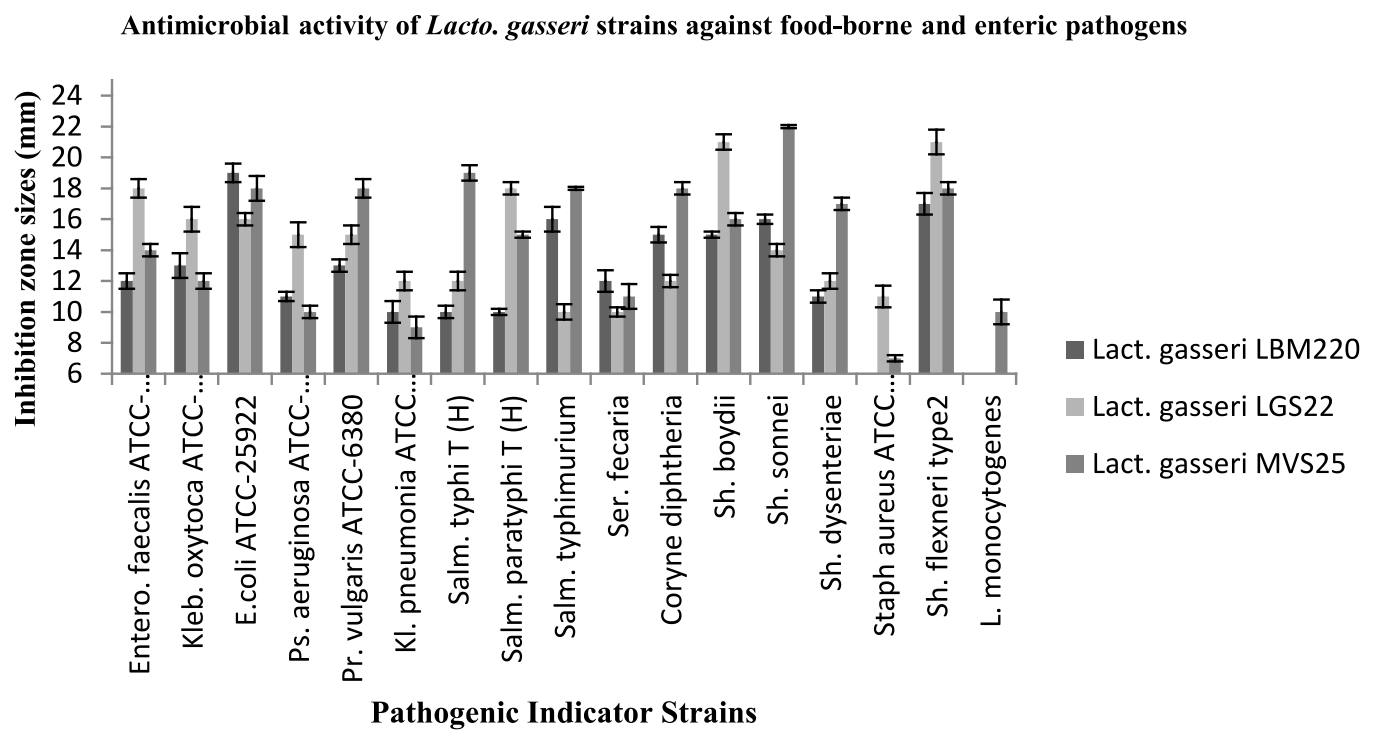

Fig. 1. Antimicrobial activity of Lact. gasseri strains against toxic food-borne and enteric pathogens The antimicrobial activities of Lact. gasseri strains against seventeen enteric pathogens were evaluated and presented by measuring the diameters of growth inhibition zones around the well as mean \pm SD from three replications. 
Time kill assay of LBM220
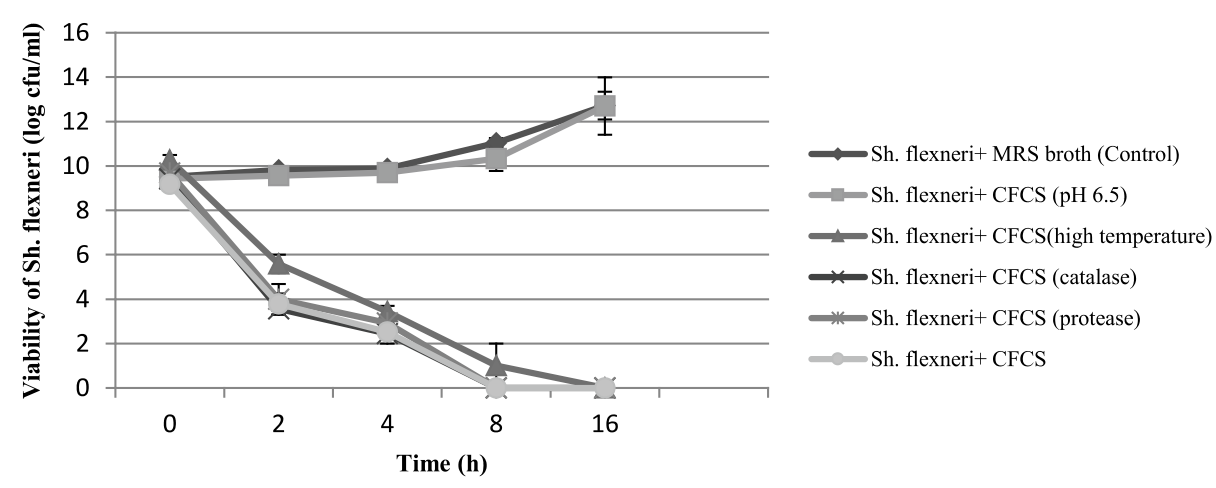

Time kill assay of MVS25
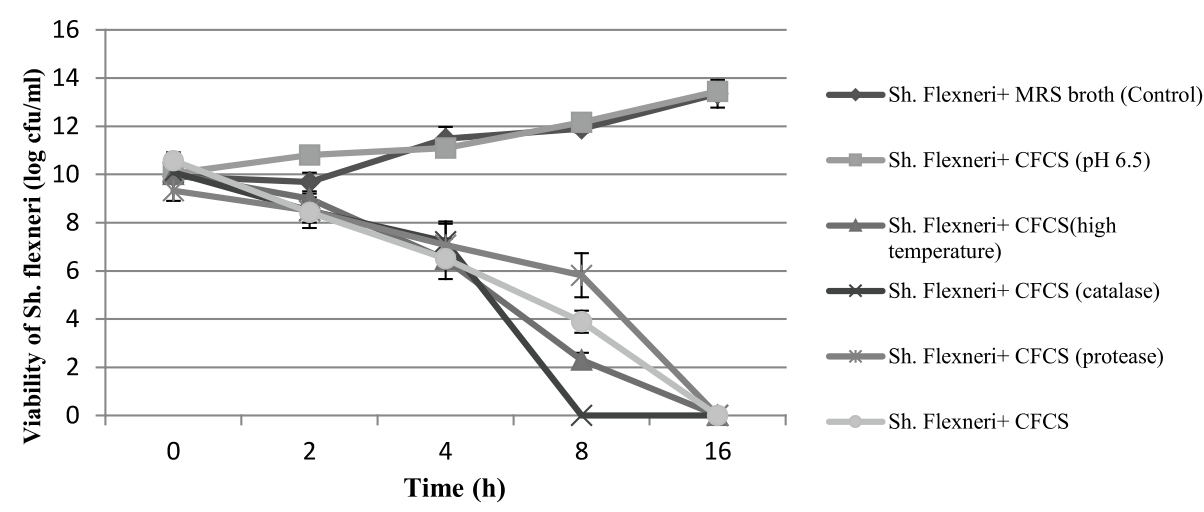

Time (h)

Time kill assay of LGS22
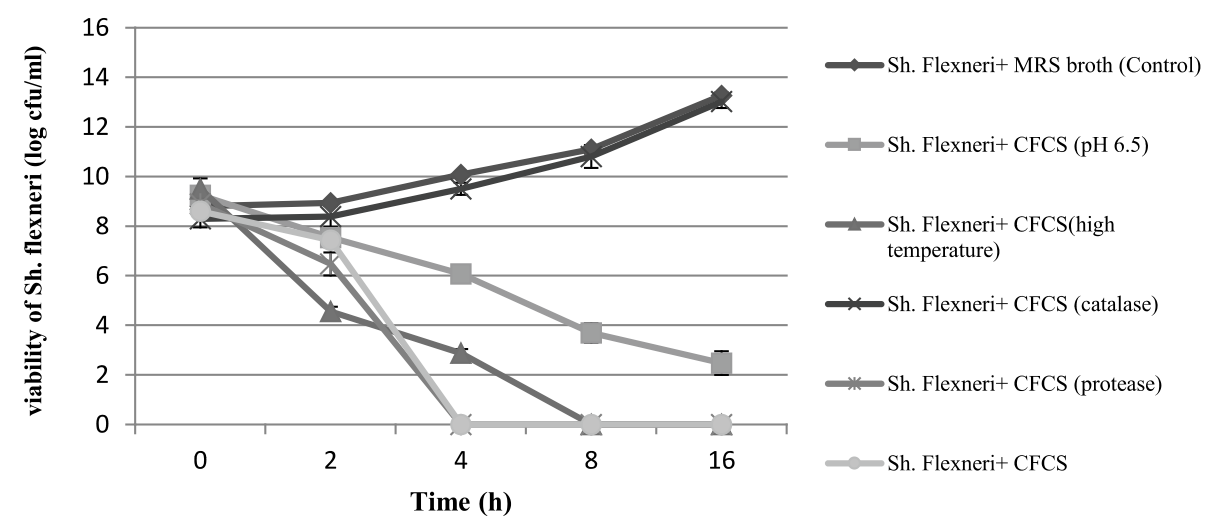

Fig. 2(A-C). Evaluation of all three Lact. gasseri strains (LBM220, MVS25 and LGS22) cell-free culture supernatant (CFCS) kill assay on pathogen Sh. flexneri by the contact time.

Sh. flexneri was incubated in untreated CFCS, CFCS neutralized to $\mathrm{pH}$ 6.5, CFCS protease treated, CFCS catalase treated, CFCS heat treated and sterile MRS broth ( $\mathrm{pH} \mathrm{6.5)}$ as control. Aliquots were removed at $0 \mathrm{~h}, 2 \mathrm{~h}, 4 \mathrm{~h}, 8 \mathrm{~h}$ and $16 \mathrm{~h}$. Serially diluted and plated on BHI to determine colony counts in log cfu $\mathrm{ml}^{-1}$. Each value is expressed as mean $\pm \operatorname{SD}(n=3)$ 
suggests that only LGS22 produce hydrogen peroxide as inhibitory metabolite. Further, when CFCSs of Lact. gasseri strains were treated with protease to determine whether their killing ability was due to bacteriocin and/or peptidal in nature, results showed no significant reduction in their antagonistic ability. Likewise, inhibitory activity of CFCSs of Lact. gasseri strains remained largely resistant to high temperature treatment.

Time-kill assay with CFCS of Lact. gasseri strains on indicator pathogen Sh. flexneri type 2

To further confirm the results obtained by agar-well diffusion method for Lact. gasseri isolates, time kill assay was also performed which demonstrated significant inhibitory activity on Sh. flexneri type 2 when co-cultured for $16 \mathrm{~h}$. The viability of Sh. flexneri after contact with CFCS, CFCS (pH 6.5), CFCS (catalase), CFCS (protease) and MRS broth (control) was assessed for five consecutive time intervals $(t=0,2,4,8,16 \mathrm{~h})$ and results displayed in Fig. 2 . It was observed that after $2 \mathrm{~h}$, the survivability of indicator pathogen decreased drastically by almost 4-5 log cfu ml-1 in presence of Lact.gasseri CFCSs, clearly elucidating its strong kill effect. When Lact.gasseri CFCSs were neutralized to $\mathrm{pH} \mathrm{6.5,} \mathrm{negligible} \mathrm{killing} \mathrm{was}$ recorded for both LBM220 and MVS25. Similarly, when CFCS was treated with catalase, only isolate LGS22 displayed no significant killing effect. However, after $16 \mathrm{~h}$ of incubation, Sh. flexneri was found to be non-viable in presence of CFCS treated with either protease or high temperature. Whereas the control, MRS broth (pH 6.5) displayed no viability loss.

\section{Antioxidant activity}

The capacity to scavenge free radicals is

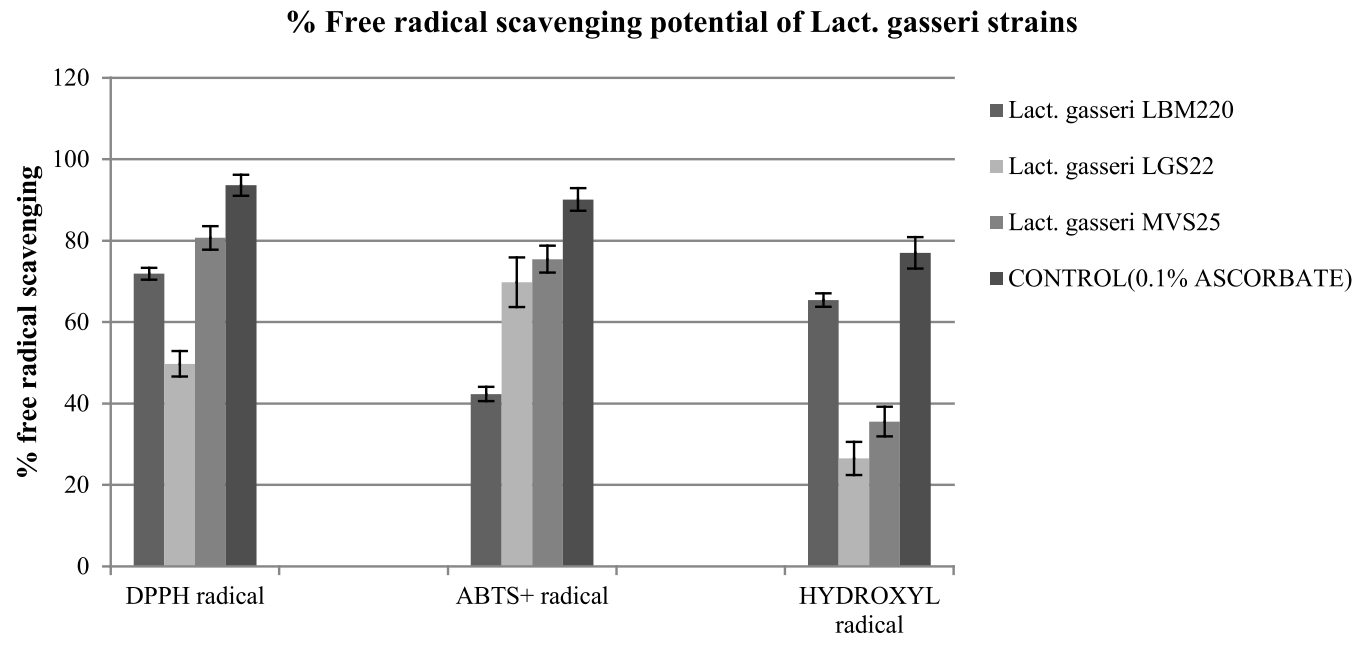

Fig. 3. Percentage free radicals scavenging potential of Lact. gasseri strains from infant faeces and human milk Scavenging effect on hydroxyl radicals, DPPH free radicals and ABTS+ radicals by culture supernatant of Lact. gasseri strains incubated at $25^{\circ} \mathrm{C}$. Each value is expressed as mean \pm S.D. $(n=3)$

Table 1. Resistance of Lact. gasseri strains at different hydrogen peroxide concentrations

\begin{tabular}{lllll}
\hline Isolates & \multicolumn{4}{c}{ Optical density at $600 \mathrm{~nm}$} \\
\cline { 2 - 5 } & $\begin{array}{l}\mathrm{O} \mathrm{mM} \mathrm{H}_{2} \mathrm{O}_{2} \\
\text { (Control) }\end{array}$ & $0.4 \mathrm{mM} \mathrm{H}_{2} \mathrm{O}_{2}$ & $0.8 \mathrm{mM} \mathrm{H}_{2} \mathrm{O}_{2}$ & $1 \mathrm{mM} \mathrm{H}_{2} \mathrm{O}_{2}$ \\
\hline Lact. gasseri LBM220 & $0.974 \pm 0.07$ & $0.554 \pm 0.08$ & $0.097 \pm 0.05$ & $0.028 \pm 0.06$ \\
Lact. gasseri LGS22 & $1.022 \pm 0.04$ & $0.945 \pm 0.07$ & $0.086 \pm 0.02$ & $0.045 \pm 0.04$ \\
Lact. gasseri MVS25 & $0.625 \pm 0.05$ & $0.451 \pm 0.04$ & $0.127 \pm 0.07$ & $0.091 \pm 0.03$ \\
\hline
\end{tabular}

Growth of test strains were evaluated by recording optical density at a wavelength of $600 \mathrm{~nm}$ after $16 \mathrm{~h}$ anaerobic incubation at $37^{\circ} \mathrm{C}$ and results expressed as mean $\pm \mathrm{SD}(\mathrm{n}=3)$ 
another valuable functional attribute of studied Lact. gasseri strains suggestive of their antioxidant property. In present study, antioxidant activity of our cultures were determined by various assays in order to establish authenticity, such as scavenging of $\mathrm{DPPH}, \mathrm{ABTS}^{+}$and hydroxyl radicals. In addition, the capacity to resist hydrogen peroxide was also studied. In presence of these free radicals, the culture supernatants of the studied strains displayed varying degree of scavenging potential, the results for which are presented in Fig. 3. For DPPH free radical, highest scavenging capacity was recorded for MVS25 (80.687\% \pm 2.89$)$, followed by LBM220 (71.884\% \pm 1.46$)$. Highest free radical scavenging for $\mathrm{ABTS}^{+}$was observed for MVS25 (75.474\% \pm 3.3$)$; while LGS22 displayed $(69.8 \% \pm 6.1)$. Highest hydroxyl free radical scavenging was observed for LBM220 (65.432\% 1.65$)$. Lact. gasseri isolates when tested for resistance to $0.4 \mathrm{mM}, 0.8 \mathrm{mM}$ and $1 \mathrm{mM}$ hydrogen peroxide for $16 \mathrm{~h}$, displayed significant viability at $0.4 \mathrm{mM}$; while viability declined drastically with increase in hydrogen peroxide concentration as reflected from the optical density (OD) values presented in Table 1.

\section{DISCUSSION}

Nowadays, application of Lactobacillus strains from human origin with superior antimicrobial potential is gaining momentum in formulation of natural therapeutics. The CFCSs of Lacto. gasseri strains isolated from breast milk and infant faeces in the present study were tested for their antagonistic ability against wide range of Gram-negative and Gram-positive pathogens. The results of present study displayed significant strain-specific inhibitory activity of all three Lact. gasseri isolates against test pathogens employed in the current study. Among gram-positive test pathogens,Staph. aureus and L.monocytogenes displayed significant resistance towards CFCS of both LBM220 and LGS22. Similar to our findings, Jose et al. $(2015)^{23}$ also reported inability of lactobacilli culture supernatants in retarding the growth of Listeria species. In addition, SerranoNino et al., (2016) ${ }^{24}$, also reported no inhibition of breast milk lactobacilli against $L$. monocytogenes and Staph. aureus. In the study, Kleb. pneumonia and Ser. fecaria were only moderately inhibited by all three strains. Interestingly, very few studies reported inhibitory activity of CFCS of human milk lactobacilli against gram negative Ser. fecaria. Similar to our results, CFCS of Lact. casei and Lact. brevis from breast milk failed to inhibit Kleb. pneumonia; while significantly inhibiting Sal. typhi, Sh. flexneri and P. aeruginosa (Sharma et al. 2017) ${ }^{25}$. The CFCSs of all three isolates strongly antagonise both Sal. typhimurium and Sal. enterica serovar Typhi in our study. Besides this, we also observed strong to moderate inhibitory activity of Lact. gasseri strains against Pr. vulgaris and $P$. aeruginosa, both of which are important opportunistic pathogens in immuno-compromised and hospitalized patients ${ }^{26}$. Gram positive test strains Sh. flexneri, Coryn. diphtheria and Sh. boydii also displayed significant sensitivity against CFCS of all three strains. However, the activity among strains is highly variable.

Breastfeeding is the copious source of lactobacilli species to the infant gut, which tends to ameliorate neonatal gastrointestinal microbial composition of lactobacilli. These species exert numerous biological functions, important among them is inhibition of toxic pathogenic microbes ${ }^{27}$. Although, the mechanism underlying antimicrobial activity by these species remain largely to be determined, probable among them is either competition for nutrients or epithelium adhesion, coaggregation of pathogens and/or production of inhibitory metabolites that include hydrogen peroxide, organic acids and bacteriocins that affect not only the toxic pathogen survivability, but may also affecttoxin production or bacterial metabolism ${ }^{7}$. In order to determine the inhibitory metabolite, CFCS was treated with catalase, $\mathrm{pH}$ adjustment, protease enzyme and high temperature. All three Lacto. gasseri culture supernatants varied in their antagonistic pattern on account of different treatments. Both Lact. gasseri LBM220 and Lact. gasseri MVS25 displayed sharp decline in antimicrobial activity when $\mathrm{pH}$ was adjusted to 6.5, while Lact. gasseri LGS22 showed disappearance of inhibitory activity on catalase treatment. These results strongly suggest the exocellular secretion of organic acids such as lactic acid and acetic acid of Lact. gasseri LBM220 and Lact. gasseri MVS25. Olivares et al., (2006) ${ }^{28}$ also reported antimicrobial activity of Lact. fermentum CECT5716 owing to its production of high amount of lactic acid. Study of Tsai et al., (2019) ${ }^{29}$, reported 
antimicrobial ability of, Lact. acidophilus RY2, Lact. salivarius MM1 and Lact. paracasei En4 isolated from infant faeces against enteropathogens. Apart from their role in effecting pathogen's metabolism and toxin production; secretion of organic acid metabolites leads to reduction in the $\mathrm{pH}$ of the micro environment, rendering obstruction to the growth of pathogens that are susceptible to acidic conditions. Also, organic acids tend to permeabilize the outer membrane of gram-negative microbes, thereby alleviating gastrointestinal infection $\mathrm{s}^{30}$. Lact. gasseri LGS22 was found to secrete hydrogen peroxide as exocellular inhibitory metabolite. Further, time kill assay confirmed the results of agar well diffusion study. As no viability loss of Sh. flexneri was observed on $\mathrm{pH}$ adjustment in case of LBM220 and MVS25, same was recorded for LGS22 in presence of catalase treated CFCS. Results also indicate sharp decline in log cfu $\mathrm{ml}^{-1}$ values of Sh. flexneri after $16 \mathrm{~h}$ co-incubation with CFCS (untreated) of all three strains. Taken together, results elucidate the effective role of Lact. gasseri strains from human origin in mitigation of gastrointestinal infections as they release antimicrobial metabolites, majorly organic acids and hydrogen peroxide that have broad antimicrobial spectrum.

The present research also strongly indicates the application of all three Lact. gasseri strains as natural antioxidant, as they significantly scavenged free radicals (80.6-26.5\%). Thus, determining the possible role of these strains in preventing the progress of several degenerate disorders caused due to oxidative stress. Oxidative stress occurs owing to disturbance in antioxidantprooxidant balance in the cell, resulting in increased intracellular levels of free radicals that cause protein denaturation, DNA hydroxylation, lipid peroxidation, and apoptosis. In presence of DPPH free radical, culture supernatant of Lact. gasseri MVS25 displayed highest scavenging ability of up to $80.69 \%$. Our results are in concordance with previous research by Gao et al., $(2013)^{31}$. Whereas, Ding et al., (2017) $)^{32}$ have reported highest DPPH scavenging activity to be 39.3\% among 23 Lactobacilli studied. Also, Lact. delbrueckii subsp. bulgaricus F17 displayed only 22.57\% DPPH scavenging (Lee et al., 2005) ${ }^{33}$. Among the reactive oxygen species, hydroxyl radicals are the most reactive radical that lead to oxidative damage of adjoining biomolecules. Induction of oxidative damage in biomolecules due to accumulation of hydrogen peroxide indirectly enhances the production of hydroxyl radicals through iron-catalyzed Fenton reactions, which can be prevented by antioxidant agents. Thus, elimination of hydroxyl radical is crucial. Our results demonstrated that Lact. gasseri LBM220 have significantly high hydroxyl scavenging ability of $65.4 \%$ as compared to previous reports on Lact. plantarum of $53 \%$ (Shi et al., 2019) ${ }^{20}$ and Lact. delbrueckii subsp. bulgaricus F17 of 59\% (Lee et al., 2005) ${ }^{35}$. Hydrogen peroxide, relatively feeble oxidant, is highly diffusive with extended lifetime, thereby contributing significantly to oxidative stress either directly or as hydroxyl radical precursor. Thus, resistance to hydrogen peroxide was studied for Lact. gasseri isolates, by recording the culture growth in presence of 0.4 $\mathrm{mM}, 0.8 \mathrm{mM}$ and $1.0 \mathrm{mM} \mathrm{H}_{2} \mathrm{O}_{2}$ for $16 \mathrm{~h}$, our results displayed significant resistance in $0.4 \mathrm{mM} \mathrm{H}_{2} \mathrm{O}_{2}$ concentration. The results are consistent with previous reports by Shi et al.,(2019) ${ }^{20}$. So far, very few studies reported the contribution of Lact. gasseri strains specifically isolated from human milk in neutralising oxidative stress molecules.

\section{CONCLUSION}

Findings from the present study report that novel Lactobacillus gasseri strains isolated from breast milk and infant faeces may find application as valuable autochthonous antimicrobial and antioxidant natural agent in food and gut matrix. However this is a preliminary study and more detailed work with prudent validation of the cytotoxic effects in in vivo models is required.

\section{ACKNOWLEDGEMENTS}

Authors thank Prof. KN Prasad, Head, Department of Microbiology, Sanjay Gandhi Postgraduate Institute of Medical Sciences for providing MALDI-TOF facility.

\section{CONFLICT OF INTEREST}

The authors declare that there is no conflict of interest.

\section{FUNDING}

None. 


\section{AUTHORS' CONTRIBUTION}

SR performed all the experiments in the laboratory and was a major contributor in writing the manuscript. VM provided the laboratory facility and analysed the results. AS conceptualised the study, analysed the results of the experiments and evaluated the manuscript. All authors have read and approved the final manuscript.

\section{ETHICS STATEMENT}

The study was approved by institutional ethical review board of Dr Ram Manohar Lohia Institute of Medical Sciences, Lucknow (Ref. No. 2784/RMLIMS/2018). Written informed consent was taken from each volunteer.

\section{DATA AVAILABILITY}

The datasets used and/or analysed during the current study are available from corresponding author on reasonable request.

\section{REFERENCES}

1. Havelaar AH, Kirk MD, Torgerson PR, et al. World Health Organization Foodborne Disease Burden Epidemiology Reference Group. World Health Organization Global Estimates and Regional Comparisons of the Burden of Foodborne Disease in 2010. PLoS Medicine. 2015;12(12):e1001923. https://doi.org/10.1371/ journal.pmed.1001923

2. Gonzalez-Torralba Ana, Garcia-Esteban Coral, JuanIgnacio Alos. Enteropathogens and antibiotics. Enfermedades infecciosas y microbiologia clinica (English ed.) 2018 36(1):47-54.

3. Zhu X, Zhao Y, Sun Y, Gu Q. Purification and characterisation of plantaricin ZJ008, a novel bacteriocin against Staphylococcus spp. from Lactobacillus plantarum ZJ008. Food Chem. 2014165:216-223.

4. Song DF, Zhu MY, Gu Q. Purification and characterization of plantaricin ZJ5, a new bacteriocin produced by Lactobacillus plantarum ZJ5. PLoS One. 2014;9(8):e105549. https://doi.org/10.1371/journal. pone.0105549

5. Aminnezhad S, Kermanshahi RK, Ranjbar R. Evaluation of synergistic interactions between cell-free supernatant of Lactobacillus strains and amikacin and genetamicin against Pseudomonas aeruginosa. Jundishapur J Microbiol. 2015;8:e16592.

6. Solls G, de Los Reyes-Gavilan CG, FernAndez N, Margolles A, Gueimonde M. Establishment and development of lactic acid bacteria and bifidobacteria microbiota in breast-milk and the infant gut. Anaerobe. 2010;16(3);307-310. https://doi.org/10.1016/j. anaerobe.2010.02.004

7. Sousa MA, RamaGR, Volken de Souza CF, Granada CE. Acid lactic lactobacilli as biotechnological toll to improve food quality and human health. Biotech Progress. 2020;e2937. https://doi.org/10.1002/ btpr.2937

8. Toba T, Yoshioka E, Itoh T. Potential of Lactobacillus gasseri isolated from infant faeces to produce bacteriocin. Lett App Microbiol. 1991;12:228-231. https://doi.org/10.1111/j.1472-765X.1991.tb00546.x

9. Mu G, Gao Y, Tuo $Y$, et al. Assessing and comparing antioxidant activities of lactobacilli strains by using different chemical and cellular antioxidant methods. J Dairy Science. 2018;101(12):10792-10806. https:// doi.org/10.3168/jds.2018-14989

10. Pourramezan Z, Kasra Kermanshahi R, Oloomi $\mathrm{M}$, Alahmadi A, Rezadoost $\mathrm{H}$. In vitro study of antioxidant and antibacterial activities of Lactobacillus probiotic spp. Folia Microbiology (Praha). 2017;63(1):31-42. https://doi.org/10.1007/s12223-017-0531-x

11. Wang $Y$, Wu Y, Wang $Y$, et al. Antioxidant Properties of Probiotic Bacteria. Nutrients. 2017;9(5):521. https:// doi.org/10.3390/nu9050521

12. Das D, A Goyal. Antioxidant activity and $\mathrm{y}$-aminobutyric acid (GABA) producing ability of probiotic Lactobacillus plantarum DM5 isolated from Marcha of Sikkim. Food Sci Techn. 2015;61(1):263-268.https://doi. org/10.1016/j.Iwt.2014.11.013

13. Kim HS, Jeong SG, Ham JS, Chae HS, Lee JM, Ahn CN. Antioxidative and Probiotic Properties of Lactobacillus gasseri NLRI-312 Isolated from Korean Infant Feces. Asian-Australasian J Animal Science. 2006;19(9):13351341.https://doi.org/10.5713/ajas.2006.1335

14. Oh NS, Joung JY, Lee JY, Kim Y. Probiotic and antiinflammatory potential of Lactobacillus rhamnosus 4B15 and Lactobacillus gasseri 4M13 isolated from infant feces. PLoS ONE. 2018;13(2):e0192021.https:// doi.org/10.1371/journal.pone.0192021

15. Rastogi S, Mittal V, Singh A. In vitro evaluation of probiotic potential and safety assessment of Lactobacillus mucosae strains isolated from Donkey's lactation. Prob Antimicrob Proteins. 2019. https://doi. org/10.1007/s12602-019-09610-0

16. Sirichokchatchawan W, Pupa P, Praechansri P, et al. Autochthonous lactic acid bacteria isolated from pig faeces in Thailand show probiotic properties and antibacterial activity against enteric pathogenic bacteria. Microb Pathogenesis. 2018;119:208-215. https://doi.org/10.1016/j.micpath.2018.04.031

17. Yu HJ, Chen YF, Yang HJ, et al. Screening for Lactobacillus plantarum with potential inhibitory activity against enteric pathogens. Ann Microb. 2015;65(3);12571265. https://doi.org/10.1007/s13213-014-0963-3

18. Zhang Y, Zhang L, Du M, et al. Antimicrobial activity against Shigella sonnei and probiotic properties of wild lactobacilli from fermented food. Microbiol Res. 2011;167(1):27-31. http://dx.doi.org/10.1016/j. micres.2011.02.006

19. Nithya V, Halami PM. Evaluation of the probiotic characteristics of Bacillus species isolated from different food sources. Ann Microbiol. 2013;63:129. https://doi.org/10.1007/s13213-012-0453-4

20. Shi Y, Cui X, Gu S, et al. Antioxidative and Probiotic Activities of Lactic Acid Bacteria Isolated from Traditional Artisanal Milk Cheese from Northeast China. Probio Antimicrob Proteins. 2019;11(4):10861099.https://doi.org/10.1007/s12602-018-9452-5 
21. Achuthan AA, Duary RK, Madathil A, Panwar H, Kumar $\mathrm{H}$, Batish VK, Grover S. Antioxidative potential of lactobacilli isolated from the gut of Indian people. Mol Biol Reports. 2012;39:7887-7897.http://dx.doi. org/10.1007/s11033-012-1633-9

22. Li S, Zhao Y, Zhang L, et al. Antioxidant activity of Lactobacillus plantarum strains isolated from traditional chinese fermented foods. Food Chem. 2012;135(3):1914-1919.https://doi.org/10.1016/j. foodchem.2012.06.048

23. Jose NM, Bunt CR, Hussain MA. Comparison of microbiological and probiotic characteristics of lactobacilli isolates from dairy food products and animal rumen contents. Microorganisms. 2015;3:198212.

24. Serrano-Nino JC, Solis-Pacheco JR, Gutierrez-Padilla JA, et al. Isolation and identification of lactic acid bacteria from human milk with potential probiotic role. JFood Nutri Res. 2016;4:170-177.

25. Sharma C, Singh BP, Thakur N, et al. Antibacterial effects of Lactobacillus isolates of curd and human milk origin against food-borne and human pathogens. 3 Biotech. 2017;7(1):31. https://doi.org/10.1007/ s13205-016-0591-7

26. Jamalifar H, Rahimi HR, Samadi N, et al. Antimicrobial activity of different Lactobacillus species against multi-drug resistant clinical isolates of Pseudomonas aeruginosa. Iran J Microbiol. 2011;3:21-25.

27. Vestman NR, Timby N, Holgerson PL, et al. Characterization and in vitro properties of oral lactobacilli in breastfed infants. BMC Microbiolog. 2013;13:193.https://doi.org/10.1186/1471-2180-13193

28. Olivares $M$, Diaz-Ropero MP, Martin R, Rodriguez JM, Xaus J. Antimicrobial potential of four Lactobacillus strains isolated from breast milk. $J$ Appl Microbiol. 2006;101(1):72-79.

29. Tsai CC, Lai TM, Hsieh YM. Evaluation of Lactobacilli for antagonistic activity against the growth, adhesion and invasion of Klebsiella pneumoniae and Gardnerella vaginalis. Indian J Microbiol. 2019;59(1):81-89. https:// doi.org/10.1007/s12088-018-0753-x

30. Mathipa MG, Thantsha MS. Probiotic engineering: towards development of robust probiotic strains with enhanced functional properties and for targeted control of enteric pathogens. Gut Pathogens.2017;9:28. https://doi.org/10.1186/ s13099-017-0178-9

31. Gao D, Gao Z, Zhu G. Antioxidant effects of Lactobacillus plantarum via activation of transcription factor $\mathrm{Nrf2}$. Food \& Function. 2013;4(6):982-989. https://doi. org/10.1039/c3fo30316k

32. Ding W, Wang L, Zhang J, et al. Characterization of antioxidant properties of lactic acid bacteria isolated from spontaneously fermented yak milk in the Tibetan Plateau. J Funct Food. 2017;35:481-488.https://doi. org/10.1016/j.jff.2017.06.008

33. Lee J, Hwang K, Chung MY, Cho DH, Park CS. Resistance of Lactobacillus casei KCTC 3260 to Reactive Oxygen Species (ROS): Role for a Metal lon Chelating Effect. Journal of Food Science. 2005;70(8):m388-m391. https://doi.org/10.1111/j.1365-2621.2005.tb11524.x 